\title{
Morphological aspects of a new type of counter electrojet event
}

\author{
R. G. Rastogi \\ Department of Physics and Space Sciences, Gujarat University, and Physical Research Laboratory, Ahmedabad 380009 , India \\ Received: January 1998 / Revised: 4 May 1998 / Accepted: 12 May 1998
}

\begin{abstract}
The study describes the time and space morphologies of a rather new type of counter electrojet event on the basis of data from the excellent chain of magnetic and ionospheric observatories along the IndoRussian longitude sector. Abnormally large westward currents are observed during almost the whole of the daytime hours on a series of days. These events do not form any vortices in the current system and do not apparently seem to be associated with tidal effects or any solar magnetosphere events or geomagnetic disturbances. The existence of a westward electric field over the equatorial ionosphere has been confirmed by the absence of an equatorial type of sporadic $\mathrm{E}$ in the ionograms at Thumba precisely during the periods when $\Delta H$ at Trivandrum minus $\Delta H$ at Alibag is negative. The equatorial $\mathrm{F}$ region anomaly was also absent on the counter electrojet day. Such counter electrojet events during the northern winter months of low solar activity years are suggested to be the result of the modified wind system in the ionosphere associated with stratospheric warming events.
\end{abstract}

Key words. Geomagnetism and paleomagnetism (time variations, diurnal to secular) - Ionosphere (electric fields and currents; equatorial ionosphere)

\section{Introduction}

Gouin and Mayaud (1967) were the first to describe the phenomenon of the daytime decrease of $\Delta H$ below the night time level at Addis-Ababa and suggested that it was due to a reversed current called counter electrojet. Rastogi (1974) described the daily, seasonal and solar cycle variations of the occurrence of counter electrojet at all equatorial observatories round the world. The counter electrojet events occurred mostly around 1600
LT in the afternoon and around $0700 \mathrm{LT}$ in the morning. Patil et al. (1990 a, b) described quantitively the occurrence of counter electrojet events in the Indian and American sector during low and high solar activity period.

Comparing the daily variations of the $H$ field at Indian stations on normal and counter electrojet days, Bhargava and Sastri (1977) isolated a semi-diurnal component of the $H$ field with maximum at about $1000 \mathrm{LT}$ and a minimum around $1500 \mathrm{LT}$. Alex et al. (1986) identified this additional semi-diurnal wave as the luni-solar tidal wave superimposed on the normal $S q$ $(H)$ field. Utilising the $D, H$ and $Z$ components of the geomagnetic field along the Indo-USSR chain of stations, Rastogi (1994) showed that the counter electrojet events at the equator were not a localised phenomenon but were associated with changes of $H$ and $D$ fields at all stations from $0^{\circ}$ to $75^{\circ} \mathrm{N}$ magnetic dip.

The establishment of an ionospheric research station by Rastogi and his group in 1963 at Thumba gave a big impetus to the studies of normal and counter electrojets. The depression of $H$ field below the night time level was shown to be associated with the reversal of ionospheric electric field at $100 \mathrm{~km}$ level and with the disappearance of the equatorial type of equatorial sporadic E layer Esq. (Rastogi et al., 1971). Later, Fambitakoye et al. (1973) showed that the disappearance of Esq and the reversal of ionospheric drift is associated with the reversal of the latitudinal profile of $\Delta H$ at low latitudes and not necessarily due to negative $\Delta H$ over the dip equator. Combining the simultaneous measurements of electron density and current in the ionospheric by rocket-borne instruments Rastogi (1972) showed that the Vertical Hall polarisation has its maximum value at $100 \mathrm{~km}$ and this, interacting with the vertical gradient of electron density, produces gradient drift instability identified on equatorial ionograms as Esq.

It was soon realised that Esq disappeared simultaneously with the reversal of ionospheric drift even though $\Delta H$ at Trivandrum was significantly above the 
night level but $\Delta H$ (Alibag) $-\Delta H$ (Trivandrum) was negative. These events were classified as the "partial counter electrojet". Rastogi (1975) explained these events as the resultant of the reversal of a current at $100 \mathrm{~km}$ simultaneously with the eastward current at $106 \mathrm{~km}$. Rastogi and Verma (1994) showed that during periods of counter electrojet (westward zonal current) the meridional component of the electrojet current is reversed towards the equator. They thus suggested a part of the meridional current as an integral part of the equatorial electrojet current superposed on the global meridional current system. James et al. (1997) have isolated this low-latitude clockwise loop current system with a focus at $15^{\circ}$ dip latitude superposed on global $S q$ current system with a counter clockwise loop with a focus at $35^{\circ}$ dip latitude.

The counter electrojet events occur generally in the afternoon or in the morning hours when the normal current is itself small. Rastogi (1997) has described that on average of above $1 \%$ of days counter electrojet events are observed around midday hours. These occurrences were found to be associated with increased disturbed activities of the Earth's magnetic field.

Rangarajan and Rastogi (1993) described a rather rare sequence of noon-time counter electrojet events in the Indian sector between 28 January, 1987 and 2 February, 1987. A large-scale parallelism between AddisAbaba and Trivandrum in respect of their diurnal and semidiurnal terms of daily variation was found but Dalat, a station further east, did not exhibit similar parallelism. Hour to hour variability observed at Trivandrum was not always reproduced at Addis-Ababa. Thus, the events were restricted at a narrow longitude sector but observed over a consecutive number of days at the same longitudes. Lunar tides were not considered to be the sole cause of these variations. Somayajulu and Cherian (1993) discussed this and other counter electrojet events at Huancayo, Addis Ababa and Trivandrum during $D$ months of low sunspot years. The events were observed at three places at same local solar time.
Hagan et al. (1992) have described ionospheric and thermospheric changes at low latitudes during minimum sunspot years in relation to the suppression of exosphere temperature at low latitudes. Somayajulu et al. (1993) reported a reversal in direction of the mean wind (from eastward to westward) between 80 and $98 \mathrm{~km}$ heights with an increased westward velocity above $100 \mathrm{~km}$ during the January, 1987 counter electrojet event. Stening et al. (1996) examined the atmospheric winds at a height of $99 \mathrm{~km}$ at Saskatoon, Canada during the counter electrojet events at Trivandrum. A reversal of the eastward wind at Saskatoon was observed during the counter electrojet events of northern winter, April and September months. The winter events generally occurred during a stratwarm.

The present work discusses in detail this special sequence of counter electrojet events, based on the analysis of all the three components of the geomagnetic field at the Indo-USSR chain of magnetic observatories. A list of these stations, together with the parameters of the geomagnetic field, are in Table 1.

\section{Data and analyses}

In Fig.1. are shown the daily variations of the horizontal $H$ field at each of the stations in Indo-USSR chain on each of the days between 26 January and 3 February, 1987. For the sake of understanding the state of geomagnetic activity the variation of the hourly values of Dst are also included in the diagram. It is to be noted that the equatorial ring current activity did not vary significantly during this period. The $A p$ index on any of the days was low, the largest being 1.0 on 29 and 1.1 on 28 January, 1987. January 30, February 2 and 3 were each one of the five IQ days of the months.

It is seen that on 27 January, 1987, there was sudden drop in the $H$ field at most of the stations in the afternoon hours similar to the changes of Dst. On 28 and 29 January an abnormally large decrease of $H$ field

Table 1. List of the geomagnetic observatories in the Indo-USSR chain together with geomagnetic field parameters during JanuaryFebruary, 1987

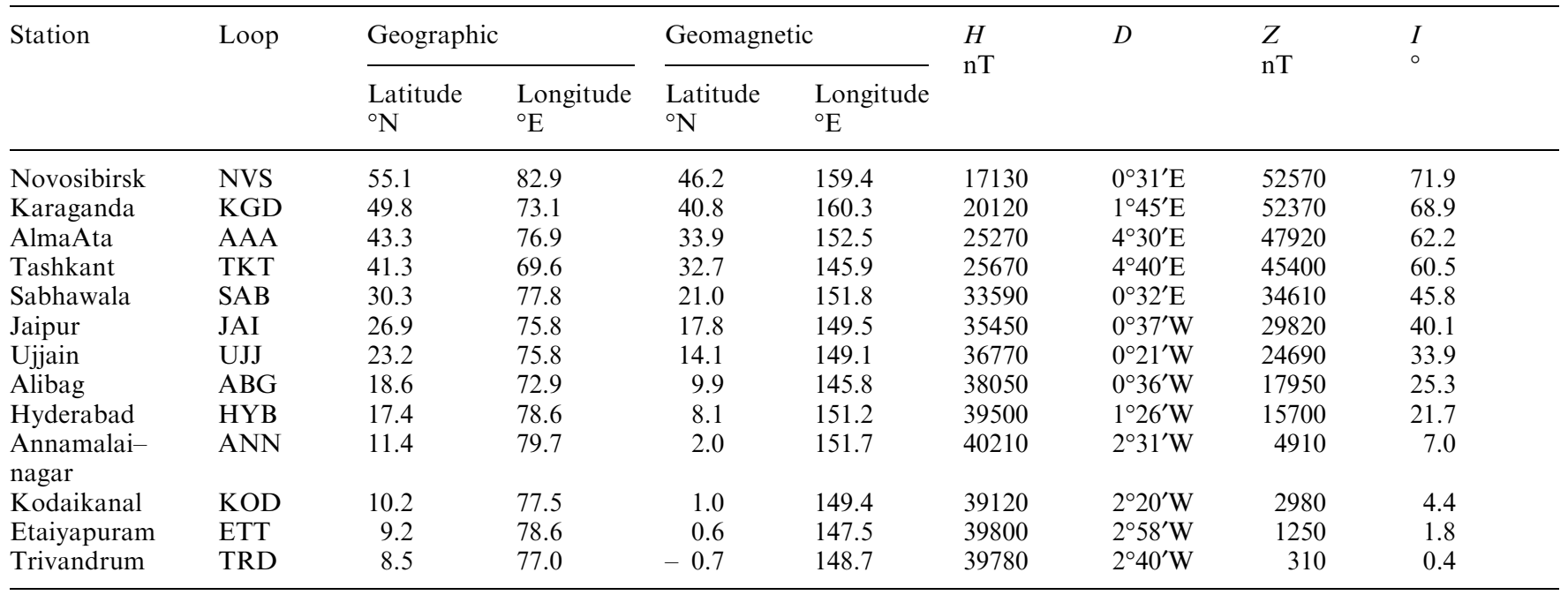




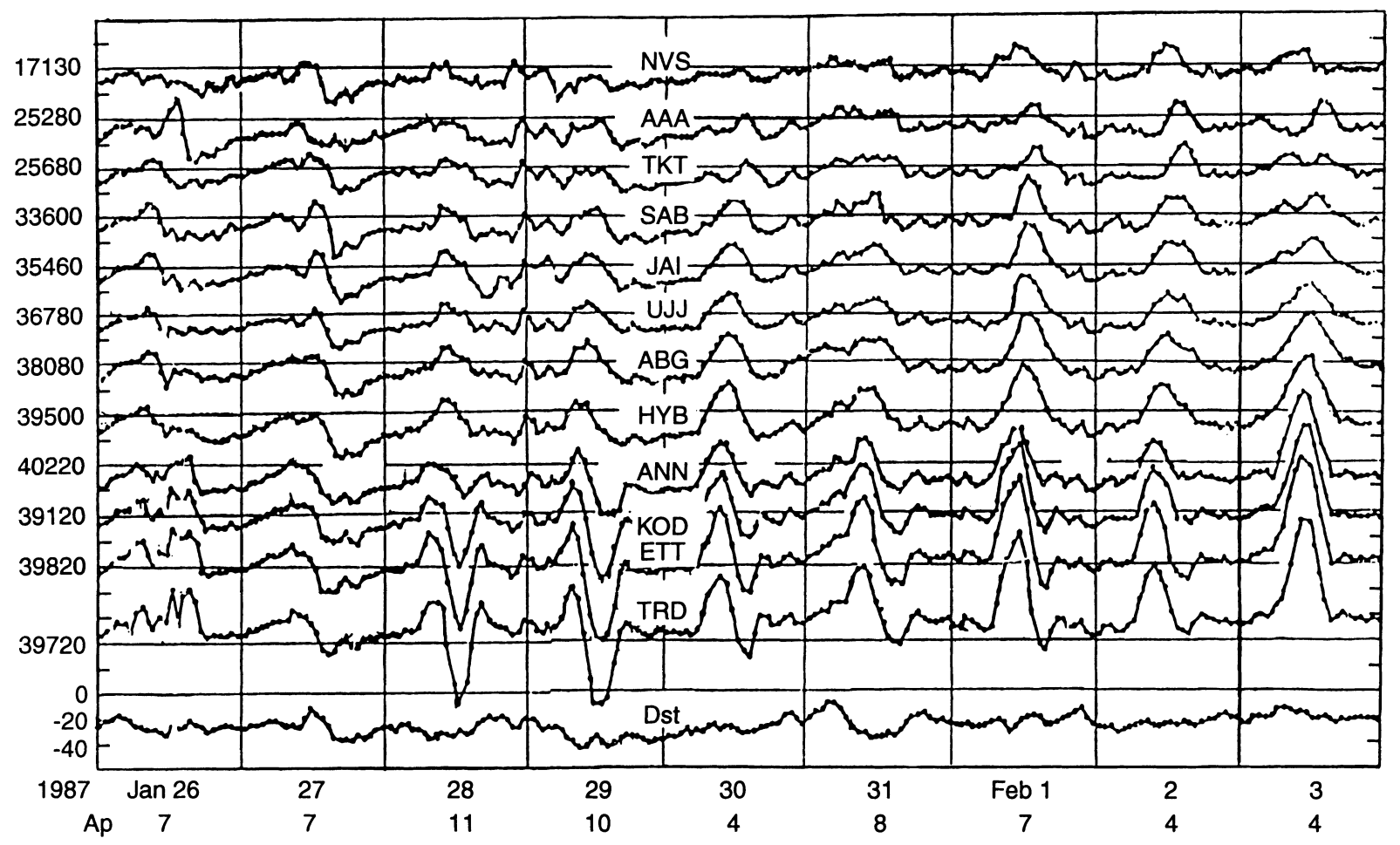

Fig. 1. Daily variations of the horizontal geomagnetic field at stations along Indo-USSR sector for the period 26 January 1987 to 3 February, 1987

occurred at all the equatorial electrojet stations, Trivandrum, Etaiyapuram, Kodaikanal and Annamalainagar. A depression of $H$ field at equatorial stations in the afternoon hours were seen on the following days. On 3 February, 1987, the $H$ field at equatorial stations showed the usual large maximum around noon hours. No effect of the depression of $H$ field between 28 January -2 February can be easily seen at low and middle latitude stations outside the region of the equatorial electrojet.

The ionospheric current system in the Central Asian sector has been shown to vary significantly with season and no loop current system can be identified during December solstices (Rastogi, 1993). Therefore, before analysing the data for the event, it was necessary to understand the normal background current system in the Central Asian sector during the months of January February, 1987. In Fig. 2. are shown the $S q$ variations of $H$ and $Y$ fields at all these stations averaged over January and February, 1987.

The $H$ field at TRD did show a prominent peak around $11 \mathrm{~h}$ and the magnitude of the midday peak decreased with increasing latitude of the station northward of TRD. Contrary to the expectations of classical variations of the $H$ field described on the basis of spherical harmonic analyses (e.g. Matsushita and Maeda, 1965; Parkinson, 1971), the daily variation of the $H$ field did not reverse at latitudes north of the $S q$ focus latitude which occurs between Sabhawala and Tashkent (Patil et al., 1983).

The $Y$ field at low latitudes showed a significant minimum around $10 \mathrm{~h}$ and a maximum around $14 \mathrm{~h}$ which is the characteristic of a southern hemispherical station. At stations further north, the same feature continued with decreasing amplitude. This too is not in conformity with the classical view of the ionospheric current system. This may be similar to the phenomenon of "invasion" described by Mayaud (1965) wherein the summer hemisphere current system pushes or "invades" beyond the magnetic equator into the winter hemisphere. However one would have to accept that the invasion extends throughout the whole hemisphere, which is not typical.

In Fig. 3. are shown the latitudinal variations of the ranges of $H$ and $Y$ fields during January - February 1987. The $H$ field range showed a rather continuous increase with decreasing latitude, in contrast to that described by Rastogi (1992) when a very sudden enhancement of $\Delta H$ was observed within $5^{\circ}$ latitude of the equator during 1978. The range for $Y$ showed a gradual increase with decreasing latitude with a maximum around the region of $3-5^{\circ}$ dip angle.

In Fig. 4 the current vectors are shown derived by combining $\Delta H$ and $\Delta Y$ at each hour at all these stations for January-February, 1987. A general impression that can be derived from the figure is of a large clockwise loop extending over the entire region and the whole daytime period with a focus somewhere south of the equator. There are no data available for the latitudes south of India and therefore a complete picture of the current system cannot be ascertained. However available data suggest that there are significant vertical/field aligned currents present at low latitudes.

From the sequence of events between 26 January and 3 February, we have selected two days (1) 3 February, 1987 when the electrojet is normal without any abnormality and (2) 29 January, 1987 when the counter 


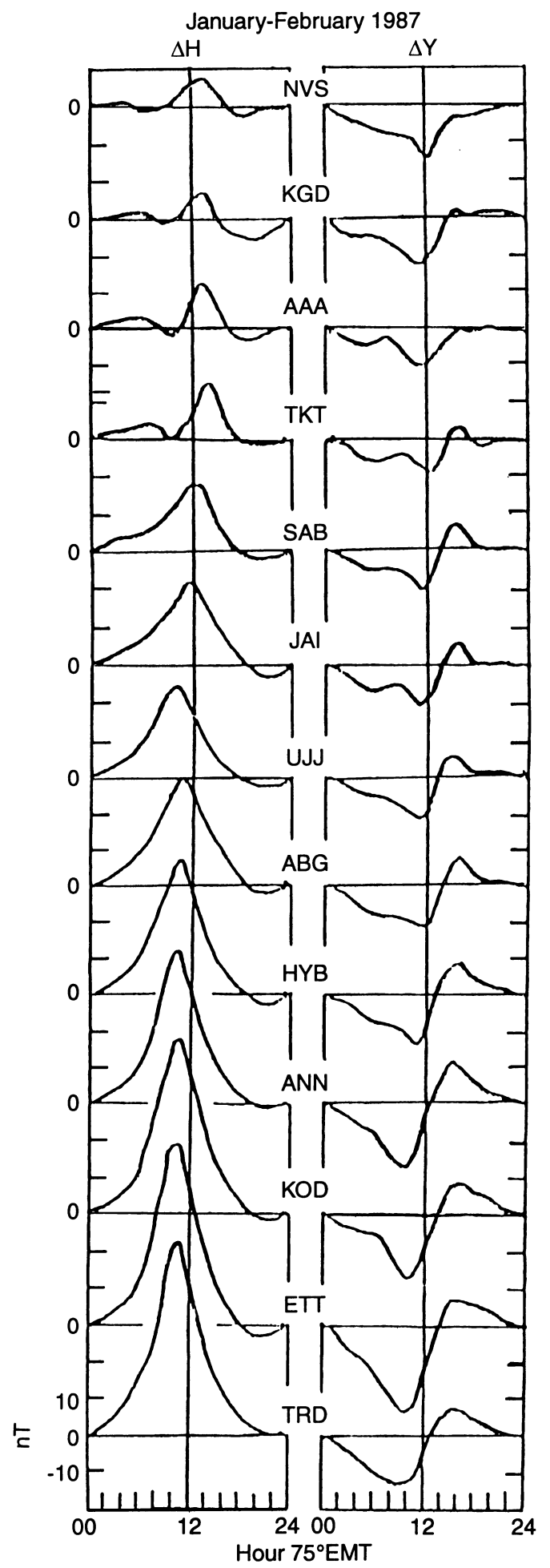

Fig. 2. Daily variations of the horizontal $(\Delta H)$ and eastward $(\Delta Y)$ fields at each station averaged for the months of January and February, 1987

electrojet is strongest. The daily variations of $H, Y$ and $Z$ fields at these stations on 29 January, 1987 and 3 February, 1987 are shown in Fig. 5 a-c.

Referring to Fig. 5a for the $H$ field, it is seen that on 3 February, 1987 the $H$ field has a peak value of $+80 \mathrm{nT}$ at $11 \mathrm{~h}$ at TRD. The $H$ range decreased with increasing

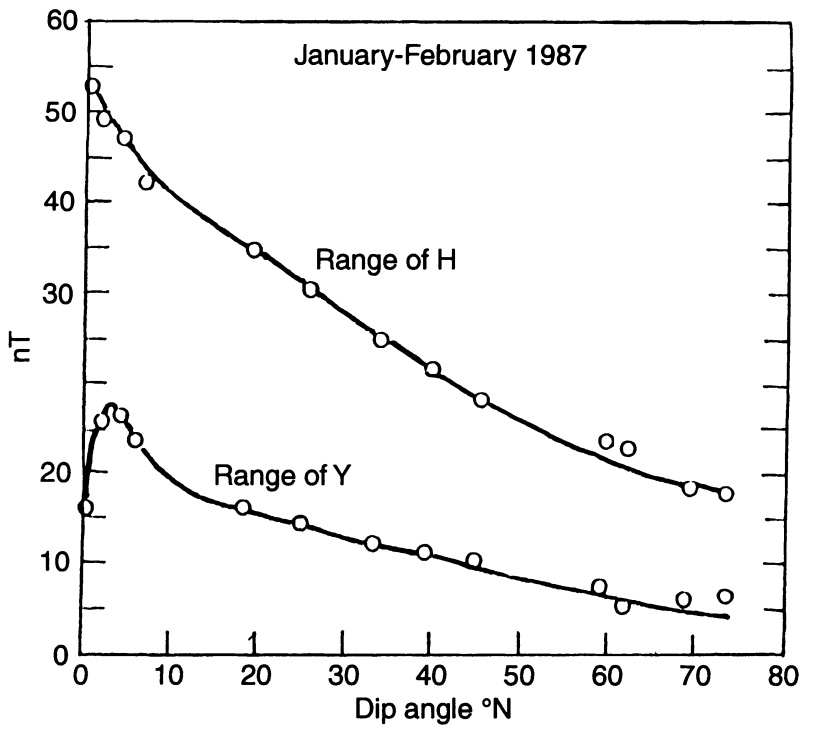

Fig. 3. The latitudinal variations of the ranges of $H$ and $Y$ fields during January-February, 1987

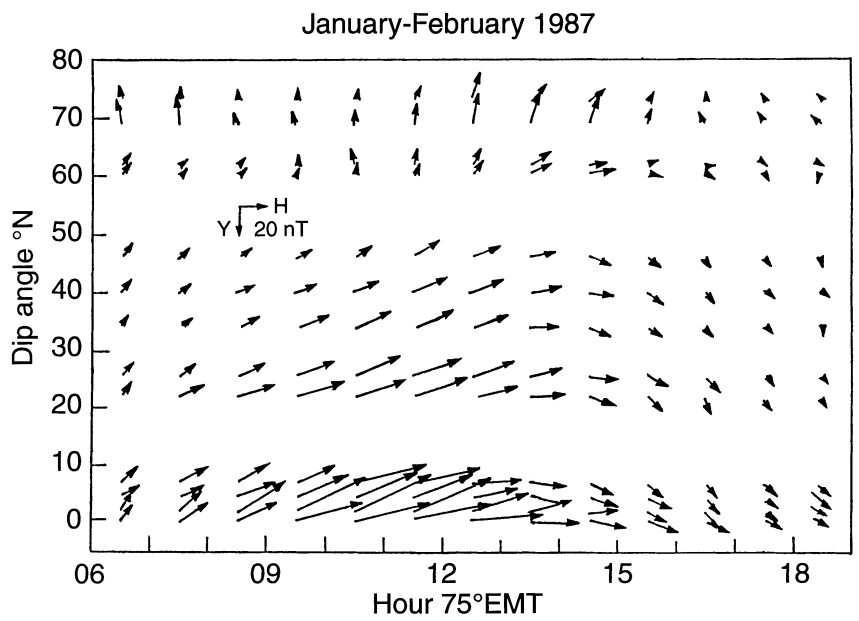

Fig. 4. The current vectors derived from $(\Delta H)$ and $(\Delta Y)$ at hourly intervals for each of the stations during January-February, 1987

latitude but remained positive even at Novosibirsk. On 29 January, 1987 the $\Delta H$ at TRD was $-55 \mathrm{nT}$ at $12.5 \mathrm{~h}$. This is probably the strongest noontime counter electrojet observed at Trivandrum. This midday depression almost vanishes for stations north of Annamalainagar.

The $Y$ field on a normal electrojet day i.e. 3 February, 1987 showed a strong minimum around $10 \mathrm{~h}$. combined with a maximum around $14 \mathrm{~h}$ at all the stations in the chain. This is a typical daily variation of $\Delta Y$ in the Southern Hemisphere. On 29 January, 1987, a counter electrojet day, a very significant positive peak was seen around midday hours at equatorial stations. At midlatitude stations the character of $\Delta Y$ remained as the characteristic southern latitude type. Thus, a strong positive deviation of $\Delta Y$ seems to be associated with a strong depression of $\Delta H$ at equatorial latitudes.

In Fig. 5c are shown the daily variations of $Z$ field at Indian stations. No $Z$ data are available to the author for 

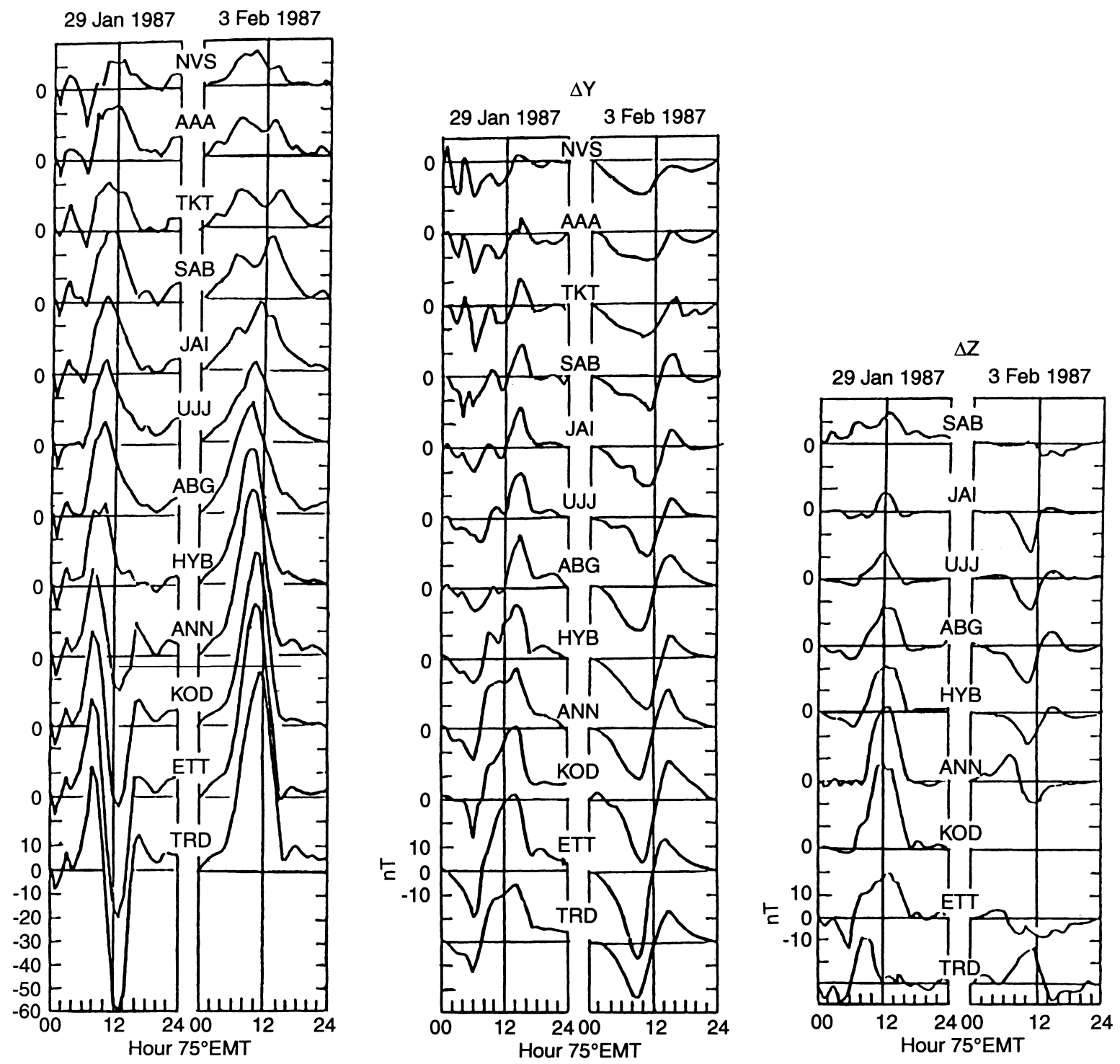

Fig. 5. a Daily variations of $H$ field at each of the stations on 29 January and 3 February, 1987. b Daily variation of $Y$ field at each of the stations on 29 January and 3 February, 1987. c Daily variations of $Z$ field at each of the stations on 29 January and 3 February, 1987

stations north of India. On 3 February, $1987 \Delta Z$ at low latitudes showed a minimum around midday as expected from an eastward flowing electrojet current. On 29 January, 1987 the $\Delta Z$ showed a broad maximum around midday hours at almost all Indian stations suggesting the effect of westward flowing ionospheric current system.

Figure 6 shows the latitudinal variations of the ranges of $H, Y$ and $Z$ fields on 29 January and 3 February, 1987. The range of $H$ on 3 February, 1987 increased monotonously with decreasing latitude as in the case of range $H$ on $S q$ days of January - February, 1987. On 29 January, 1987 the ranges were only slightly larger for stations north of Ujjain but it decreased sharply with decreasing latitude reaching a value of -55 nT at TRD. From this curve it seems that HYB and ABG were also affected by the counter electrojet phenomenon.

The range shown by $Z$ was negative at all low and middle latitude stations on 3 February, 1987 but were positive at all Indian stations confirming the reversal of the direction of currents in the electrojet region.

Defining $Y$ max as the maximum value and $Y$ min the minimum value during the day irrespective of the time it occurred, the latitudinal variations of these parameters were not different on either of the days 29 January or 3 February, 1987. However, the values of $Y$ $\min$ or $Y$ max at any of the stations were more positive on counter than on normal electrojet days.

Figure 7 shows the daily variations of $\Delta H$ and $\Delta Y$ at each of the stations on 29 January minus on 3 February, 1987 in order to estimate the additional currents on the midday counter electrojet day. A very large negative peak of $\Delta H$ about $120 \mathrm{nT}$ is seen at Trivandrum. With increasing latitude the magnitude of negative $\Delta H$ decreases, but can be seen very clearly at Hyderabad and to a lesser extent at ABG and UJJ. It is interesting to note that a large depression of $\Delta H$ at about $06 \mathrm{~h}$ was observed at almost all stations but 


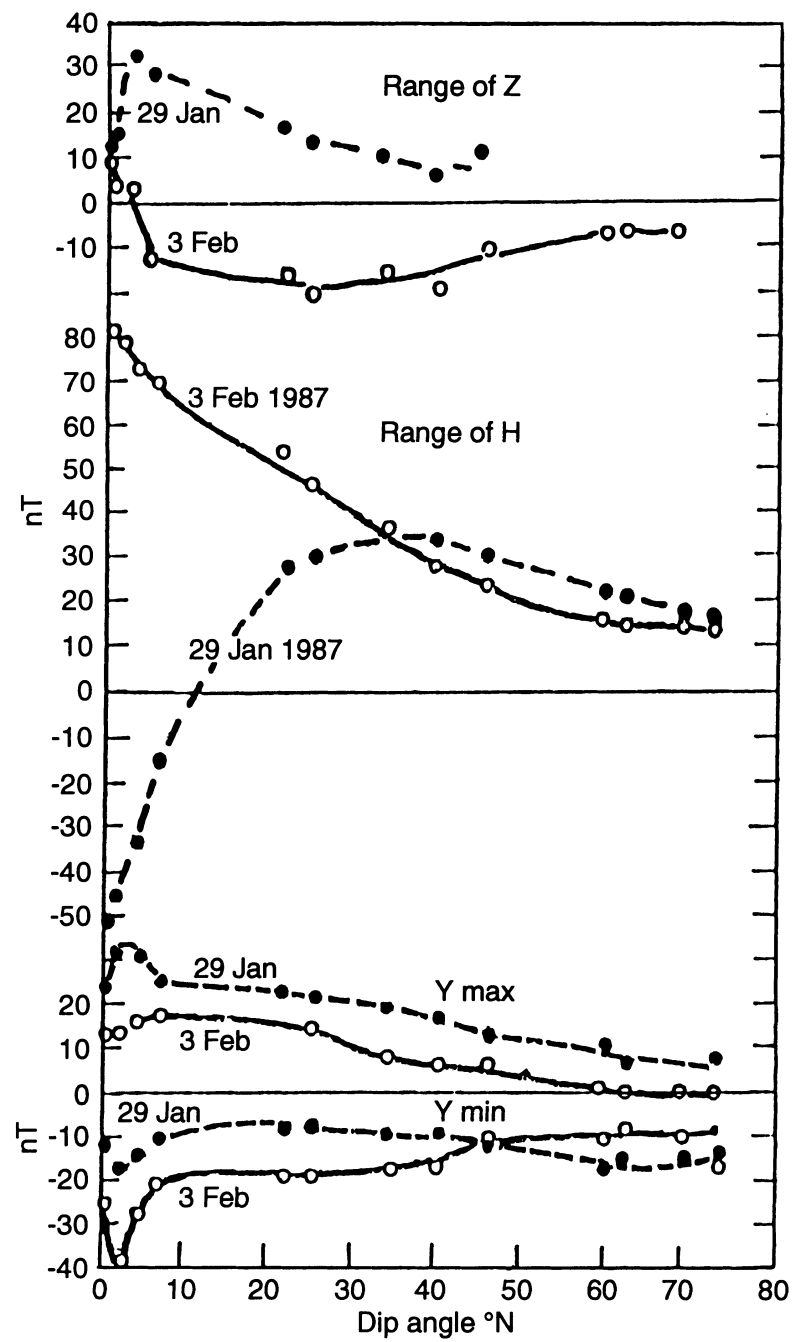

Fig. 6. Latitudinal variations of the ranges of $H, Z$ and $Y$ fields on 29 January and 3 February, 1987

the magnitude $\Delta H$ decreased with decreasing latitude. Does this mean that the event of 29 January had a combined source of auroral as well as at equatorial latitudes?

Regarding $\Delta Y$, a very large positive peak was observed at all stations from TRD to TKT.

These data strengthen the earlier suggestion of Rastogi (1994) that the major counter electrojet events are not confined to equatorial latitudes only but are the consequence of some global disturbance occurring along a particular longitude sector.

These results conform to an earlier conclusion by Rastogi and Verma (1994) that the westward zonal equatorial electrojet current is associated with the reversal of equatorial meridional current from a northward to southward direction.

Figure $8 \mathrm{a}, \mathrm{b}$ shows the current vectors at different stations for each hour of daytime on 3 February and 29 January, 1987. The current system was very similar on 3 February to the average of all $S q$ days in January and February, 1987. The equatorial currents were, however, stronger on 3 February than on average $S q$ days and the

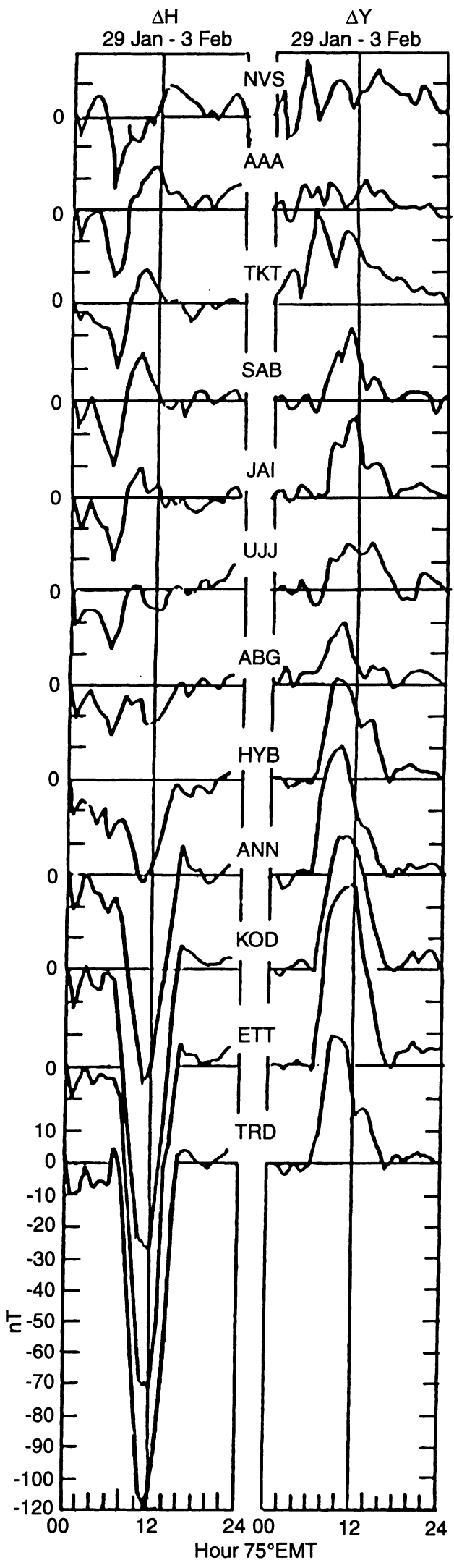

Fig. 7. The daily variations of $\Delta H$ and $\Delta Y$ at each of the stations on 29 January, 1987 and on 3 February, 1987 


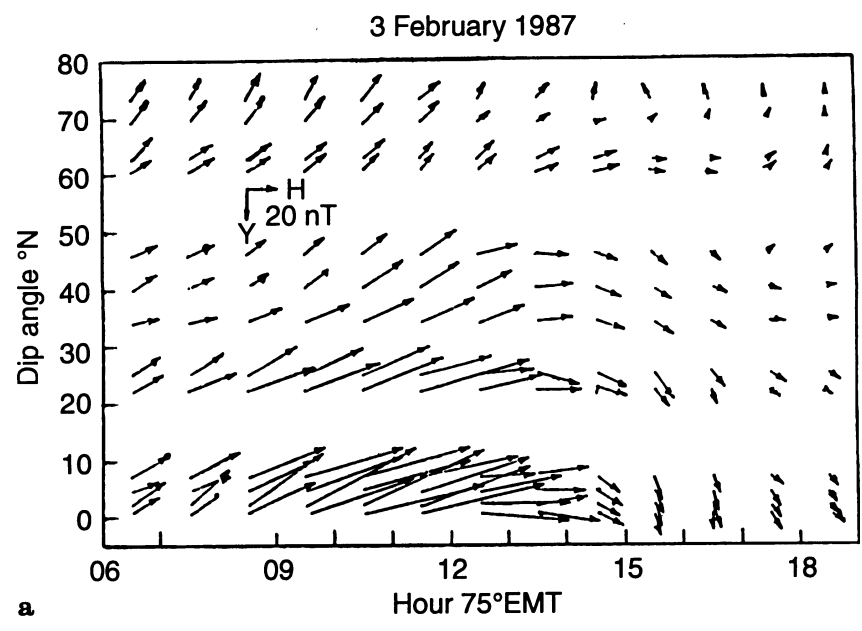

29 January 1987

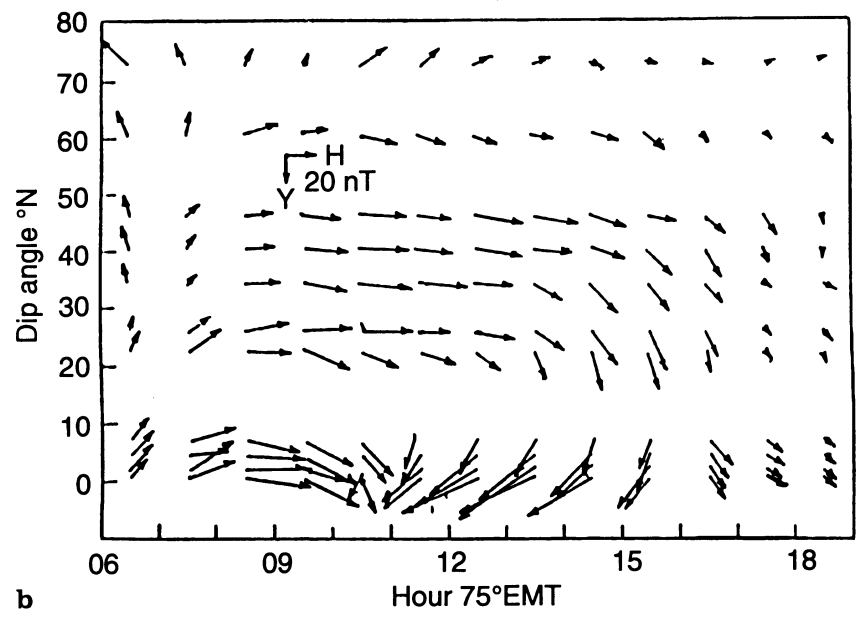

Fig. 8. a The current vectors at different stations at each hour during daytime on 3 February 1987 a normal electrojet day; b the current vector at different stations at each hour during daytime on 29 January 1987, a counter electrojet day

current loop seems to turn around earlier in the afternoon hours.

Regarding 29 January, 1987, the current vectors during forenoon hours were similar to those on 3 February, 1987. Between 10 and $15 \mathrm{~h}$ the vectors turned around towards west and a small incomplete loop appeared around $10^{\circ}$ dip around $14 \mathrm{~h}$. Again, the complete picture of current system could not be computed due to absence of any data from the Southern Hemisphere.

\section{Ionospheric effect of counter electrojet}

The decrease of $\Delta H$ at an equatorial station below the night time level was first shown by Rastogi et al. (1971) to be associated with the reversal of equatorial ionospheric electric field and the sudden disappearance of the equatorial sporadic E layer, Esq.

The ionospheric station at Thumba, close to Trivandrum record on a regular basis the vertical incidence ionograms at intervals of 15 minutes. Some selected ionograms at Thumba on 29 January and 3 February, 1987 are reproduced in Fig. 9.

On 3 February, 1987, a strong normal electrojet day Esq first appeared at $0800 \mathrm{~h}$ and continued to be present on every $15 \mathrm{~min}$ ionogram till $1445 \mathrm{~h}$ and then suddenly disappeared on the $1500 \mathrm{~h}$ ionogram. On 29 January, 1987, Esq first appeared at $0630 \mathrm{~h}$ and continued to $100 \mathrm{~h}$. The Esq disappeared at $1015 \mathrm{~h}$ and continued to be missing on each 15 min ionogram till $1630 \mathrm{~h}$ but then reappeared at $1645 \mathrm{~h}$. This confirms independently that on 29 January, 1987 the ionospheric electric field on the magnetic equator was westward from $1015 \mathrm{~h}$ to $1630 \mathrm{~h}$.

Rastogi and Patil (1986) have shown that $\Delta H$ (Trivandrum - Alibag) is very closely related to the Doppler shift of the VHF back scatter echoes at Thumba, which in itself is proportional to the strength of the electric fields in the E region of the ionosphere. It has been shown by Alex et al. (1986) that $\Delta H$ (Huancayo - Fuquene) is related to the occurrence of backscatter echoes on Jicamarea VHF Radar. A positive value of $\Delta H$ (HUA-FUG) is associated with the occurrence of $\mathrm{E}$ region irregularities while with $\Delta H$ (HUA-FUG) turning negative the irregularities disappear almost instantaneously. In Fig. 10 are shown the instantaneous values at each 15 min interval of $\Delta H$ (TRD-ABG) on the days when the ionosonde records are available at Thumba. The first appearance and last appearance of $E s-q$ echoes are shown by upward pointing arrows while the disappearance of $E s-q$ echoes are indicated by downward pointing arrows. On February, 3, 1987, Esq first appeared at $0800 \mathrm{~h}$ when $\Delta H$ (TRD-ABG) became positive and continued till $1445 \mathrm{~h}$ as long as $\Delta H$ (TRDABG) remained positive. On 29 January, 1987, Esq is present on $0630 \mathrm{~h}$ to $1000 \mathrm{~h}$ as long as $\Delta H$ (TRD-ABG) remains positive, Esq remains absent from $1015 \mathrm{~h}$ to $1630 \mathrm{~h}$ when $\Delta H$ (TRD-ABG) is negative. It is remarkable that $E s q$ was absent precisely during the intervals when $\Delta H$ (TRD-ABG) remained negative. Using simultaneous in situ measurements of the electron density $N$, and electric current $J$, Rastogi (1972) showed that the electron density of gradient and the Hall polarisation field occur at $100 \mathrm{~km}$ whereas the electron drift velocity is at maximum around $108 \mathrm{~km}$. The Esq was shown to occur precisely at $100 \mathrm{~km}$ at any of the electrojet stations and thus was associated with cross-field irregularities. Rastogi et al. (1975) showed that the growth rate of cross-field irregularities at the $100 \mathrm{~km}$ altitude should be less than one minute and showed that Esq scatter echoes in the ionograms could disappear or appear within two consequtive ionograms taken one minute apart.

Another manifestation of the equatorial electric fields during daytime hours is the development of equatorial $\mathrm{F}$ region fountain of plasma from equator to mid latitudes. This is accompanied by the uplifting of the $\mathrm{F}$ region of the ionosphere over the equator together with the decrease of $f_{0} \quad \mathrm{~F}_{2}$. These facts can be easily ascertained from the Thumba ionograms. On 3 February, 1987 the height of $F_{2}$ layer is clearly seen to be significantly higher than the height of $F_{2}$ layer at corresponding times on 29 January, 1987. Further, the maximum frequency reflected from the ionosphere is 

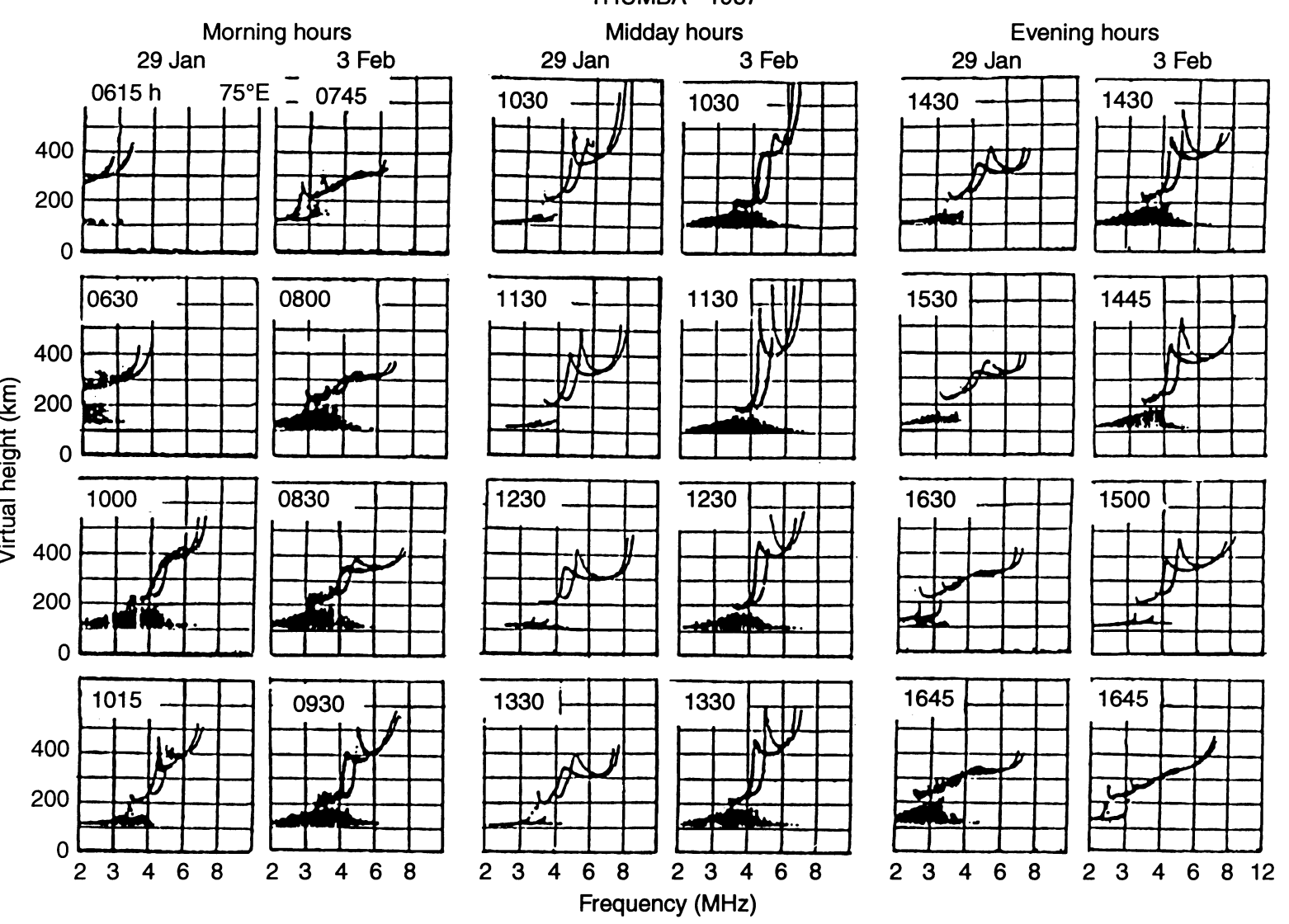

Fig. 9. Some selected ionograms at Thumba on 29 January and 3 February, 1987

clearly reduced during the midday hours on 3 February than on 29 January, 1987. Figure 11 shows the daily variation of $\left(f_{0} \mathrm{~F}_{2}\right)$ and $\mathrm{hpF}$ (or $\left.\mathrm{F}_{2}\right)$ on January 29, 1987 a strong electrojet day, $\mathrm{F}_{2}$ showed a noon bite out with maxima at 09 and $16 \mathrm{~h}$ but, on January 29, 1987, a counter electrojet day, $f_{0} \mathrm{~F}_{2}$ showed a single maximum at $1230 \mathrm{~h}$. Corresponding hpF i.e. the height of peak of F layer shows significantly higher values of February 3 than on January 29, 1987.

\section{Discussion}

The existence of a westward current during the counter electrojet events were shown by experimental data with reversal of equatorial ionospheric electric field on the basis of HF radar measurements (Crochet et al., 1979) as well as by VHF radar measurements (Woodman et al., 1977), Rastogi and Patel. (1975) showed the reversal of an equatorial electrojet current associated with the northward turning of the interplanetary magnetic field. Statistically, the occurrence of the morning as well as the afternoon counter electrojet events were shown to be closely related to the phases of the moon. Rastogi (1981) classified two types of counter electrojet events: (1) having a slow decrease and recovery of the $\Delta H$ values extending over a period of some $6 \mathrm{~h}$, associated with Iuni-solar tides; (2) a sudden decrease of $\Delta H$ observed simultaneously at all equatorial latitude stations along a longitude sector, and extending for a shorter period are associated with magnetospheric interaction with solar wind. Comparing the daily variations of $\Delta H$ at low and middle latitude stations on counter and normal electrojet days, a semi-diurnal component of $\Delta H$ was isolated (Bhargava and Sastri, 1977; Rastogi, 1994) Recently, James et al. (1997) have isolated the additional current system superimposed on a normal $S q$ current system during a partial electrojet event.

The present observations of counter electrojet is very. different to the ones so far described (1). This event is abnormally strong, the net westward current is almost of the same magnitude as the normal eastward current during normal electrojet days. Thus, the additional current is superimposed on the normal $S q$ current (2). The event occurs on a series of days and takes four to five days for recovery of the normal conditions (3). The events are not associated with any spurt of magnetic activity (4). The events were not observed at stations seperated in longitude by more than $2-3 \mathrm{~h}$ (5). The additional current system does not show any vortex system associated with any semi-diurnal currents.

The events described here do not seem to be associated with any magnetic disturbances. Rangarajan and Rastogi (1993) have concluded that the occurrence of the counter electrojet on successive days in January February, 1987 does not coincide well with the lunar 


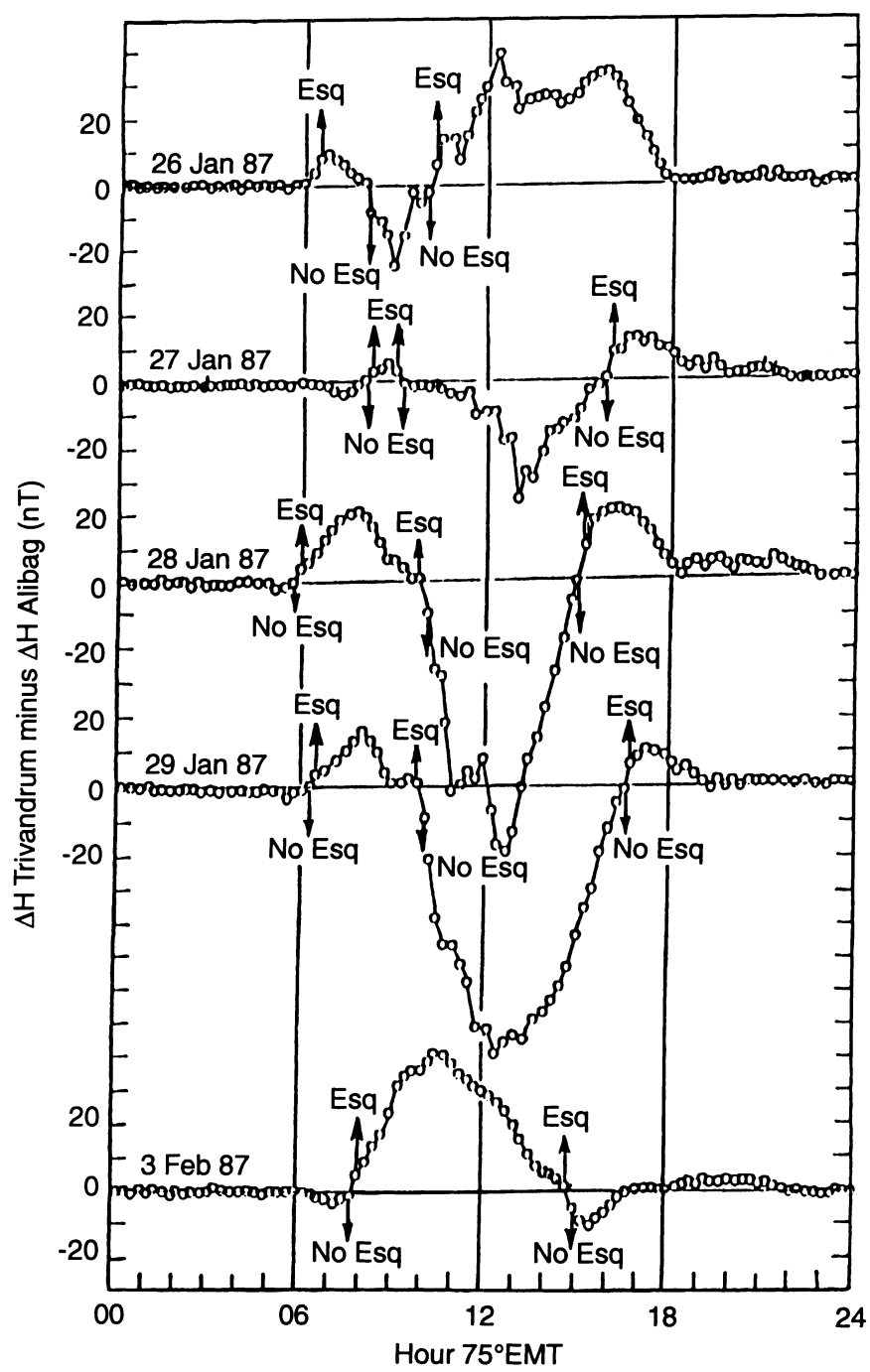

Fig. 10. Daily variations of the strength of equatorial electrojet, devoted by $\Delta H$ (Trivandrum minus Alibag), with the times noted for the appearance and disappearances of equatorial $E s(E s q)$ for some of the days in January-February, 1987

tidal effect. They also showed that this particular event occurred within a limited longitude sector and was not evident on nearby electrojet stations to the east and west of Trivandrum.

Blanc and Richmond (1980) suggested a different mechanism for the generation of an anti $S q-H$ electric field at the equatorial regions called the 'disturbance atmospheric dynamo'. They simulated numerically the ionospheric winds produced by auroral heating during magnetic storms. They found that an 'anti-Sq.' type of current vortex results such that the electric field and current at low latitudes vary in opposition to their normal quiet day behaviour. The disturbance dynamo generally fully develops a day after the onset of the storm and subsides on subsequent days.

The present event described here is very different to the effects of the disturbance dyanmo. Firstly the normal strength of the electrojet at Trivandrum on these days was about $+80 \mathrm{nT}$ and on 28, 29 January, 1987 the midday values of $\Delta H$ were about $-60 \mathrm{nT}$. Thus, the

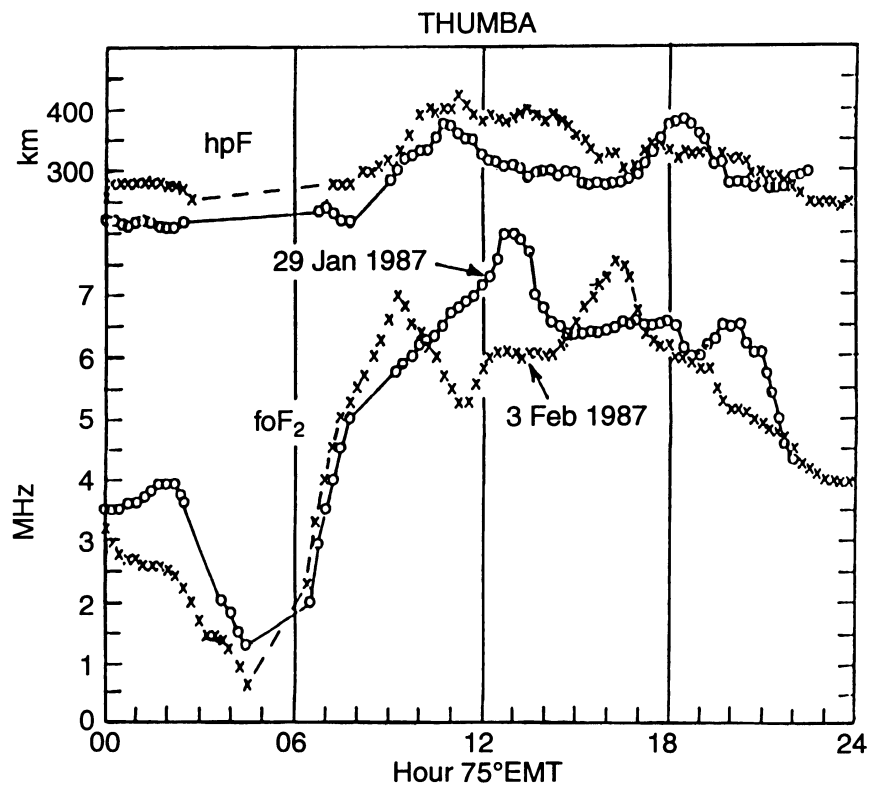

Fig. 11. Solar daily variations of the critical frequency, $f_{0} \mathrm{~F}_{2}$, of the $\mathrm{F}_{2}$ layer and the height of the peak electron density $\mathrm{hpF}$ of the $\mathrm{F}$ region at Thumba on the normal electrojet day (3 February, 1987) and on counter electrojet (29 January, 1987) day.

westward electric field should have been strong enough to generate westward current with ground $\Delta H$ of -140 $\mathrm{nT}$ and to produce a counter electrojet of $-60 \mathrm{nT}$ on two successive days. It took about six days for this effect to fade out completely. The most important feature of the phenomenon was its confinement within a narrow longitude sector successively for a number of days. This is analogous to the meteorological disturbances sometimes remaining at a location for days at a time. It does seem to be a predominant semi-diurnal wave causing the phenomenon whose phase seems to be opposite to the corresponding wave on normal electrojet days.

Hagan and Salah (1988) reported an unexpected suppression of the exosphere temperature $(T \infty)$ derived from incoherent scatter radar measurements at low latitudes with respect to middle latitude $T \infty$ measurements as well as to the model prediction. They suggested that upward propagating semi-diurnal tides could be responsible for the observed latitudinal variation in $T \infty$. Later Hagan et al. (1992) examined additional evidence of weather variability during solar minimum winter. They suggested that the coupling between the lower and upper atmosphere is responsible for the observed weather patterns. Despite remarkably similar geophysical conditions characterising the in situ forcing of the upper atmosphere during solar minimum winter months, it is significant that variability in the observations of the ionosphere and thermosphere at low latitudes is observed. Somayajulu et al. (1993) described the results of meteor wind and ionospheric sounding measurements at the electrojet station Trivandrum during the January 1987 counter electrojet events. The mean zonal winds in the altitude range $90-105 \mathrm{~km}$ were, in general, westward during the counter electrojet days and eastward during normal electrojet days. The 
phases and amplitudes of the tidal components on the counter electrojet days were found to be substantially different from those on the normal electrojet days. Stening et al. (1996) described the upper atmospheric winds at a height of $99 \mathrm{~km}$ at Saskatoon, Canada, during counter electrojet events at Trivandrum, one of which happened to be January, 1987 event. They showed that 8 out of 10 events were associated with westward excusions in the mean wind between 90 and $100 \mathrm{~km}$ at Saskatoon and 7 out of 10 of these occur during stratospheric warming conditions.

Thus, it is getting clearer that the phenomenon of the counter equatorial electrojet is a complex one which is driven by a global system of winds and electric fields, the sources of which may be very varied ones.

Acknowledgements. Grateful thanks are due to the council of Scientific and Industrial Research, India as well as the Indian National Science Academy for supporting the research activities of the author. Thanks are also due to Indian Institute of Geomagnetism, Mumbai, National Geophysical Research Institute Hyderabad, Indian Institute of Astrophysics, Bangalore, IZMIRAN, Moscow and Prof V.V. Somayajulu for providing the data used in the present analyses. Special thanks are also due to Physical Research Laboratory and Gujarat University, Ahmedabad for providing the necessary facilities for the scientific activities of the author and co-workers. Thanks are also due to Prof. R.J. Stening for useful suggestions specially with regards to the relationships of the counter electrojet events during geomagnetic quiet days to the neutral wind system and the statospheric warming events.

Topical Editor D. Alcayde' thanks R.J. Stening for his help in evaluating this paper.

\section{References}

Alex, S., A. R. Patil, and R. G. Rastogi, Equatorial counter electrojet, solution of some dilema, Ind. J Radio Space Phys., 15, 114-118, 1986.

Bhargava, B. N., and N. S. Sastri, A comparison of days with and without occurrence of counter electrojet afternoon events in the Indian region, Ann. Geophys., 33, 329-333, 1977.

Blanc, M., and A. P. Richmond, The ionospheric disturbance dynamo, J. Geophys. Res., 85 (A4), 1669-1686, 1980.

Crochet, M. C. Hanuise, and P. Broche, HF radar studies of two stream instability during an equatorial counter-electrojet, J. Geophys. Res. 84 (A9), 5223-5233, 1979.

Fambitakoye, O., R. G. Rastogi, J. Tabbagh, and P. Vila, Counter electrojet and Es-q disappearance, J. Atmos. Terr. Phys., 35, 1119-1126, 1973

Gouin, P., and P. N. Mayaud, A propos de L'existence possible d'un centre electrojet aux latitudes magnetiques equatoriales, Ann. Geophys. 23, 41-47, 1967.

Hagan, M. E., and J. E. Salah, Effects of geomagnetic activity in winter thermosphere Magnetically undisturbed conditions, J. Geophys. Res. 93, 9927-9935, 1988.

Hagan, M. E., C. A. Barth, W. K. Tobiska, A. H. Manson, R. A. Vincent, M. J. Buonsanto, R. G. Burnside, and V. B. Wickwar, Observations of upper atmospheric weather during solar minimum winter, J. Geophys. Res. 97 (A4), 4163-4164, 1992.
James M. E., D. R. K. Rao, and R. G. Rastogi, Identification of the current system associated with a partially reversed equatorial electrojet, J. Geomagn. Geoelectr. 49, 633-640, 1997.

Matsushita, S., and H. Maeda, On the geomagnetic solar quiet daily variation field during the IGY, J. Geophys. Res., 70, 25352558, 1965.

Mayaud P. N., Analyse morphologique de la variabilite jour-a-jour de la variation journaliere reguliere $S_{R}$ du champ magnetique terrestre II Le systeme de courants $\mathrm{Cm}$ (regions non-polaires), Ann. Geophys. 21, 514-544, 1965.

Parkinson, W. D., An analysis of the geomagnetic diurnal variation during the International Geophysical Year, Gerlands, Beitr. Geophysik, Leipzig, 80(2/3), 199-232, 1971.

Patil, A. R., D. R. K. Rao, and R. G. Rastogi, Equatorial electrojet strength in the Indian and American sectors, Part I, During low solar activity, J. Geomagn. Geoelectr., 42, 801-811, 1990a. Part II, During high solar activity, J. Geomagn. Geoelectr., 42, 813823, 1990 b.

Rangarajan, G. K., and R. G. Rastogi, Longitudinal difference in magentic field variations associated with quiet day counter electrojet, J. Geomagn. Geoelectr., 45, 649-656, 1993.

Rastogi, R. G., Equatorial sporadic E and plasma unstabilities, Nature, 237, 73-75, 1972.

Rastogi, R. G., Westward equatorial electrojet during day time hours, J. Geophys. Res., 79(10), 209-214, 1974.

Rastogi, R. G., On the simultaneous existence of eastward and westward flowing equatorial electrojet current, Proc. Ind. Acad. Sci. 81A, 80-92, 1975.

Rastogi, R. G., Equatorial counter electrojet and the interplanetary magnetic field, Ind. J. Radio Space Phys., 10, 1-15, 1981.

Rastogi, R. G., Equatorial sporadic E and plasma instabilities, Nature 237, 73-75, 1992.

Rastogi, R. G., Ionospheric current system associated with equatorial counter electrojet, J. Geophys. Res., 99 (A7) 13209-13217, 1994.

Rastogi, R. G., Midday reversals of equatorial ionospheric electric fields, Annales Geophysicae, 15, 1309-1315, 1997.

Rastogi, R. G., and V. L. Patel, Effect of interplanetary magnetic field on ionosphere over the magnetic equator, Proc. Ind. Acad. Sci., 82(4), 121-141, 1975.

Rastogi, R. G., and A. R. Patil, Complex structure of equatorial electrojet current, Current Sci., 55 (9), 433-436, 1986.

Rastogi, R. G., and S. D. Verma, Abnormal reversal of meridional and zonal equatorial electrojet currents, Ind. J. Radio Space Phys. 23, 387-392, 1994a.

Rastogi, R. G., H. Chandra, and S. C. Chakravarty., The disappearance of equatorial Es and the reversal of electrojet current, Proc. Ind. Acad. Sci., A.74, 62-67, 1971.

Rastogi, R. G., M. R. Deshpande, and A. Sen, Equatorial sporadic $\mathrm{E}$ and growth rate of associated irregularities, Geophys. Res. Lett., 2, 496-498, 1975.

Somayajulu, V. V., and L. Cherian, Longitudinal extent of counter electrojet events, Rev. Brasil. Geofis., 11(3), 355-364, 1993.

Somayajulu, V. V., L. Cherian, K. Rajeev, G. Rajkumar, and C. R. Reddi, Mean wind and tidal components during counter electrojet events, Geophys. Res. Lett., 20 (14), 1443-1446, 1993.

Stening, R. J., C. E. Meek, and A. H. Manson, Upper atmosphere wind systems during reverse equatorial electrojet events., Geophys. Res. Lett. 23 (22), 3243-3246, 1996.

Woodman, R. F., R. G. Rastogi, and C. Calderon, Solar cycle effects on the electric fields in the equatorial ionosphere, J. Geophys. Res. 82 (32), 5257-5260, 1977. 